BMJ Paediatrics Open

\title{
Responding to the changing burden of disease for children and adolescents in modern Britain: the RCPCH State of Child Health Report 2017
}

Russell M Viner, ${ }^{1,2}$ Emily Kate Arkell, ${ }^{2}$ Melissa Ashe, ${ }^{2}$ Melanie Simpson ${ }^{2}$

To cite: Viner RM, Arkell EK, Ashe M, et al. Responding to the changing burden of disease for children and adolescents in modern Britain: the RCPCH State of Child Health Report 2017. BMJ Paediatrics Open 2017;1:e000026. doi:10.1136/ bmjpo-2017-000026

Received 2 September 2017 Revised 5 0ctober 2017 Accepted 7 October 2017

\section{CrossMark}

${ }^{1}$ Population, Policy and Practice Research Programme, UCL Institute of Child Health, London, UK

${ }^{2}$ Royal College of Paediatrics and Child Health, London, UK

Correspondence to Professor Russell M Viner; r. viner@ucl.ac.uk

\section{ABSTRACT}

The Royal College of Paediatrics and Child Health published the State of Child Health (SOCH) 2017, summarising the changing burden of disease in UK children and young people (CYP) over the past 20 years. These data show clearly that the three great challenges of our time for CYP are obesity, mental health problems and the impact of poverty and inequality on health. In this review, we summarise key findings from SOCH 2017 and outline key responses the UK must make to improve health and well-being for its CYP.

\section{BACKGROUND}

The State of Child Health (SOCH) 2017 report, published by the Royal College of Paediatrics and Child Health (RCPCH) in January 2017, brought together data on key measures of the health of children and young people (CYP) across the four UK countries over a 20-year time horizon. ${ }^{1}$ The 25 included indicators ranged from specific conditions including asthma and diabetes, key drivers of morbidity including injuries, health determinants such as breast feeding and obesity to behaviours such as smoking and alcohol. Indicators were chosen by a panel of experts, based on consultation with a panel of CYP from the RCPCH @Us Network about areas important to CYP and families. Key considerations were the following: (1) indicators related to major areas of health burden in the UK; (2) authoritative published data were available for at least two of the four UK countries and (3) historical data were available over the past two decades or longer.

The report documents the changing nature of burden of disease for CYP across all four UK countries, in particular the shift towards environmental causes of mortality and morbidity as part of the epidemiological transition seen across high-income countries. ${ }^{2}$ An understanding of this shifting burden of disease is essential for rational planning of health services and public health responses. In this review, we summarise key findings from SOCH 2017 and outline key evidencebased response the UK must make to improve health and well-being for its CYP.

A second key element of SOCH 2017 was undertaking international comparisons across the indicators, essentially asking how the UK was doing compared with other wealthy countries in Europe. This was particularly prompted by previous work suggesting the UK was lagging behind comparators across a range of child health outcomes. ${ }^{34}$

We found a picture of overall progress in CYP health over the past 20 years in the UK, but progress is patchy and the UK has fallen behind other wealthy countries in many areas over the past 20 years. Indeed, it was difficult to identify any indicator outside of injuries in which the UK was the leader in Europe.

We identified three great challenges for CYP in modern Britain, related to the epidemiological transition noted above. The two great epidemics of our children's time are obesity and mental health problems, both of which are products of dramatic social, economical and environmental change over the past 30 years. The third great challenge is poverty and its twin, inequality, which blight the lives of our CYP across nearly all health outcomes.

These chime with the key concerns of CYP themselves. To inform the report's findings, we interviewed CYP who told us they want to be involved in the discussions and decisions that affect their health. Mental health and the effects of poverty were their key concerns.

In the UK, there are an estimated 850000 CYP with mental health problems. Half of lifetime mental health problems start before the age of $14 \%$ and $75 \%$ by 24 years ${ }^{5}$, making early identification and intervention essential. CYP mental health is finally on the priority list 


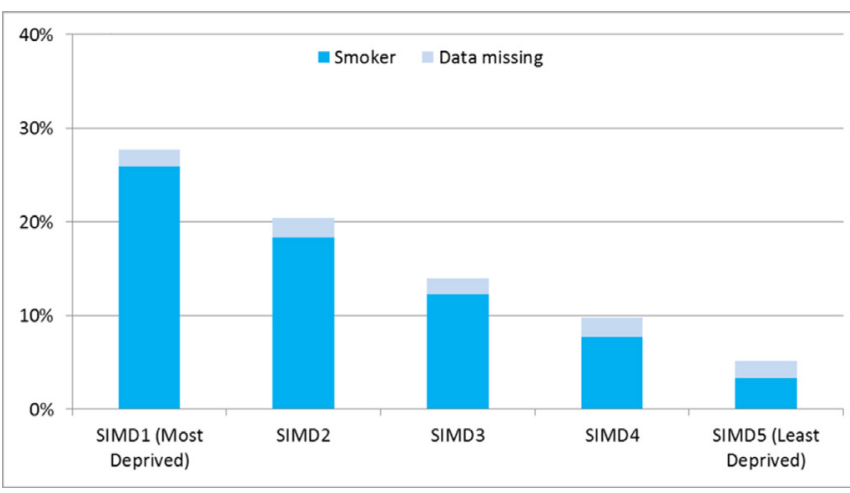

Figure 1 Proportion of mothers smoking at the first health visitor review, Scottish Index of Multiple Deprivation (SIMD) 2012 quintile, year ending $31{\text { March } 2015 .{ }^{7}}^{2}$

for policy-makers and government. While each nation of the UK has produced reports that have sought to support improvements in the ways that services are commissioned for CYP suffering with mental health problems, there is a significant lack of data on the prevalence and experience of mental health problems in CYP across the UK.

Similarly, crucial data are missing that assess growth and weight status of children through to adolescence. The report includes an indicator for healthy weight status at commencement of primary school (aged 5), measured across three countries, although the indicator for healthy weight at end of primary school (aged 10-11 years) was available in only one of the four countries. However, data are lacking on the weight trajectories of these children from birth and in the years before school entry and then again as they transition into adolescence and adulthood. Given the substantially increased risk posed to overweight and obese children, intervening at an early stage as possible is crucial in order to reduce the probability that these children will experience serious lifelong problems as a result of their weight status at childhood.

Inequality blights our children's lives and the SOCH 2017 Report carefully examined this. We found that CYP from deprived backgrounds have much worse health and well-being outcomes than their better-off peers across every indicator in the report, bar one. For example, in 2015/2016, 40\% of CYP in England's most-deprived areas were overweight or obese, compared with $27 \%$ in the most-affluent areas. Tackling child poverty will require a multipronged approach to truly grapple with many of the preventable health issues that are crippling CYP. It is crucial that governments consider the impacts to CYP in their policy-making across all sectors, particularly fiscal policy, housing and education as well as health and social care.

The third key element of SOCH 2017 was an outline of a path to improvement for each indicator for each UK country. The Report identifies a clear direction of travel for each indicator with clear recommendations that urgently require action to reduce the cost of the burden of disease for CYP in modern Britain. Putting children first will require each government in the UK to develop a child health and well-being strategy that is prioritised, implemented and coordinated using an accountability framework that includes professionals, the public and civil society. Evaluating this strategy will keep us on course for ensuring that children all over the UK, regardless of their background, will have equal access to healthcare that will give them the best start in life.

\section{HIGHLIGHTS OF THE SOCH 2017}

The SOCH report has uniquely pulled together comparable data to provide an overview of the state of CYP health across the UK. Each indicator was chosen based on the availability of data from at least two of the nations of the UK and a life course approach coupled with a social determinants model was used to identify and steer the areas of focus for the report.

\section{Maternal health}

Maternal health and well-being has a profound impact on the health of infants and children in the UK. Smoking during pregnancy is one of the most important modifiable risk factors for improving infant health and efforts to eliminate all exposure of tobacco in the womb must be prioritised. ${ }^{6}$ If smoking rates of the most-deprived mothers in Scotland were to fall to those in the least-deprived areas, there would be over 6000 fewer women smoking at their first health visitor review.

In Scotland (figure 1 ) over a quarter $(25.9 \%)$ of women in the most-deprived areas were recorded as smokers at their first health visitor review following the birth of their baby compared with only $3.3 \%$ in the least-deprived areas. ${ }^{7}$ Given the strong relationship between social deprivation and a range of major risk factors for poor child health, including smoking in pregnancy and lower breastfeeding rates, ${ }^{8}$ there is a need for joined up national public health campaigns that promote good health and well-being during and after pregnancy and use graduated universalist approaches to ensure a focus on the most deprived.

\section{Breast feeding}

Breast feeding provides a broad range of benefits to CYP that span across their lifetime. The UK aligns its recommendations with $\mathrm{WHO}^{9}$ that promotes breast feeding as the optimal method in which to improve child development and reduce health costs, which is surprising given that data show only $23 \%$ of mothers in Northern Ireland and $27 \%$ of mothers in Scotland were recorded as breast feeding at their $6-8$ week health visitor review in 2014/2015 $5^{10} 11$ (figure 2). An analysis of global breast feeding at 6 months found that in the UK only $34 \%$ of babies were fed through breast milk (either solely or in addition to formula feeding) compared with $49 \%$ in the USA and $71 \%$ in Norway. ${ }^{12}$ Promoting breast feeding is therefore a low cost opportunity to optimise our children's health and development. 


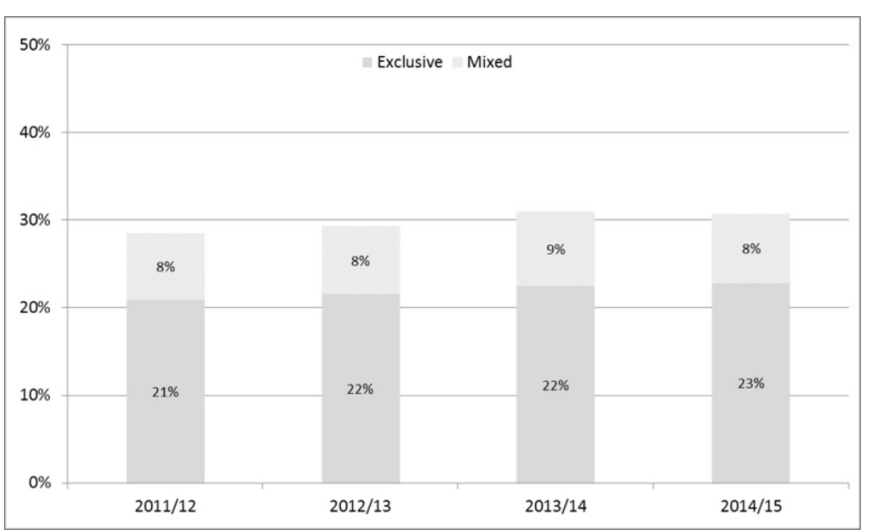

Figure 2 Proportion of women recorded as breast feeding at 6-8 week review in Northern Ireland, 2011/2012 to $2014 / 2015 .^{11}$

Despite the available evidence to support the benefits that breast feeding has to protecting babies from risk of gastrointestinal, respiratory and ear infections, to name a few, the reasons behind the UK's low breastfeeding rates remain complex. It was a huge blow to public health campaigns tasked with promoting breast feeding when the Infant Feeding Survey was cancelled in 2015. UK-wide breastfeeding comparison data were collected via this survey every 5 years from 1975 . These data showed that $81 \%$ of mothers who breast fed for less than a week and $86 \%$ of mothers who breast fed for between 1 and 2 weeks would have liked to have breast fed for longer. ${ }^{13}$ Without these data, it is impossible to tailor services to ensure the right support is available at the right time for mothers that will improve the population uptake of breast feeding and will improve the duration in which mothers choose to breast feed their babies. In doing so, it will enable a better response to the growing volume of evidence that demonstrates the benefits received by CYP down the line; promoting stable weight status and reducing the risk of these CYP developing diabetes. ${ }^{14}$

Stronger efforts need to be made by governments, health agencies and services to ensure that parents are informed about the importance of breast feeding. The SOCH report strongly recommends for services to provide antenatal education and health promotion information about breast feeding to both parents. Maternity services will need to achieve and maintain the Unicef Baby Friendly Initiative ${ }^{15}$ accreditation that will support parents to build close relationships with their infants and support optimum health and development. Parliaments can also make a bold influencing statement by supporting breast feeding in parliamentary chambers.

\section{Key messages}

The RCPCH has recently released a new position paper on breast feeding. ${ }^{16}$ Key recommendations include:

- Governments across the UK to update or develop new national strategies to promote breast feeding.

- Governments across the UK to require all maternity services to achieve and maintain Unicef UK Baby
Friendly Initiative accreditation; this requirement is currently met by all maternity units in Scotland and Northern Ireland.

- The National Health Service (NHS) in England, Wales, Scotland and Northern Ireland to ensure the preservation of universal midwifery services and universal health visiting services.

- Employers to ensure career or lifetime salaries are not adversely effected by a woman's choice to breast feed.

- UK Government to legislate for breastfeeding breaks and facilities suitable in all workplaces for breast feeding or expressing breast milk.

\section{Obesity}

The growing obesity crisis is no longer just a problem for the NHS, it is an epidemic that presents one of the greatest health threats to CYP across the globe. ${ }^{17}$ Ensuring children enter primary school at a healthy weight is crucial to promoting better health outcomes in later life. It will reduce their risk of developing type 2 diabetes, high blood pressure and cardiovascular disease, and will also support children to attain and achieve better education outcomes as well as promoting their self-esteem and body image.

The 'obesogenic environment' or role that environmental factors play in determining both nutrition and physical activity presents government with an opportunity to develop a far-reaching strategy to tackle the obesity crisis that goes further than what is proposed in England's Childhood Obesity Plan. It is recommended that children entering primary education should not have more than $19 \mathrm{~g}$ of sugar in a day, which far exceeds that of a can of cola which often has 35g. The recent passing of the Soft Drinks Industry Levy (which will be implemented in April 2018) is a huge victory for child health and with robust independent evaluation government will be in a better position to develop regulatory frameworks to ensure measures are taken to achieve a substantial reduction in sugar intake for all CYP.

To tackle the underlying causes and risks that fuel obesity in childhood, responsibility must be maintained by all sectors, professions, communities and individuals from town planners and local authorities striving to protect our green spaces to enable CYP to have space for play and exercise, through to top-level policy-making to target and regulate the food industry. Removing advertising and targeted messaging to CYP that promote the 'eat fast, move less' message is critical. The UK Governments must introduce a ban on advertising foods high in saturated fats, sugar and salt before $9 \mathrm{pm}$. Research is also required to generate an evidence base for the impact of online food marketing to CYP, which will enable health services to design evidencebased programmes that will effectively assess and respond to CYP who present with unhealthy weight status.

Assessing and recognising the healthy weight of CYP is an essential part of developing a coordinated approach towards tackling childhood obesity. It is estimated that at least one-third of parents in England are unable to recognise 
that their child is overweight and while some data are collected through national measurement programmes in England, Scotland and Wales (figure 3), missing data in the UK presents gaps in knowledge on the multitude of factors contributing to childhood obesity. Expanding programmes to measure the height and weight of infants and children after birth, before school and in adolescence across the four nations will ensure interventions are targeted during critical periods in the life course.

\section{Key messages}

- Enact cross-government childhood obesity strategies across all countries, including rigorous evaluation and quality improvement plans.

- Robust evaluation to monitor the effectiveness of the proposed sugar levy and other sugar-reduction initiatives in all countries.

- Expand nutritional standards to all schools.

- Make school-based health education a statutory subject in all schools, with schools focusing on the importance of both physical activity and nutrition.
- Introduce a ban across the UK on the advertising of foods high in saturated fats, sugar and salt before9 $9 \mathrm{pm}$, and evaluate the impact of online food marketing on children.

- Join-up measurement of children from birth through to school-age to allow tracking and early identification of overweight children.

- Support a research environment that enables sustained, long-term expansion of basic science and applied research to identify the causes of obesity and effective interventions to tackle it.

- Ensure that overweight and obese children have timely access and support to attend evidence-based programmes.

\section{Tobacco and alcohol}

Income inequality and access to education are among the strongest determinants of adolescent health. ${ }^{18}$ CYP from deprived areas are much more likely to smoke than their wealthier peers and are likely to start smoking at a younger age (figure 4). Smoking continues to be the

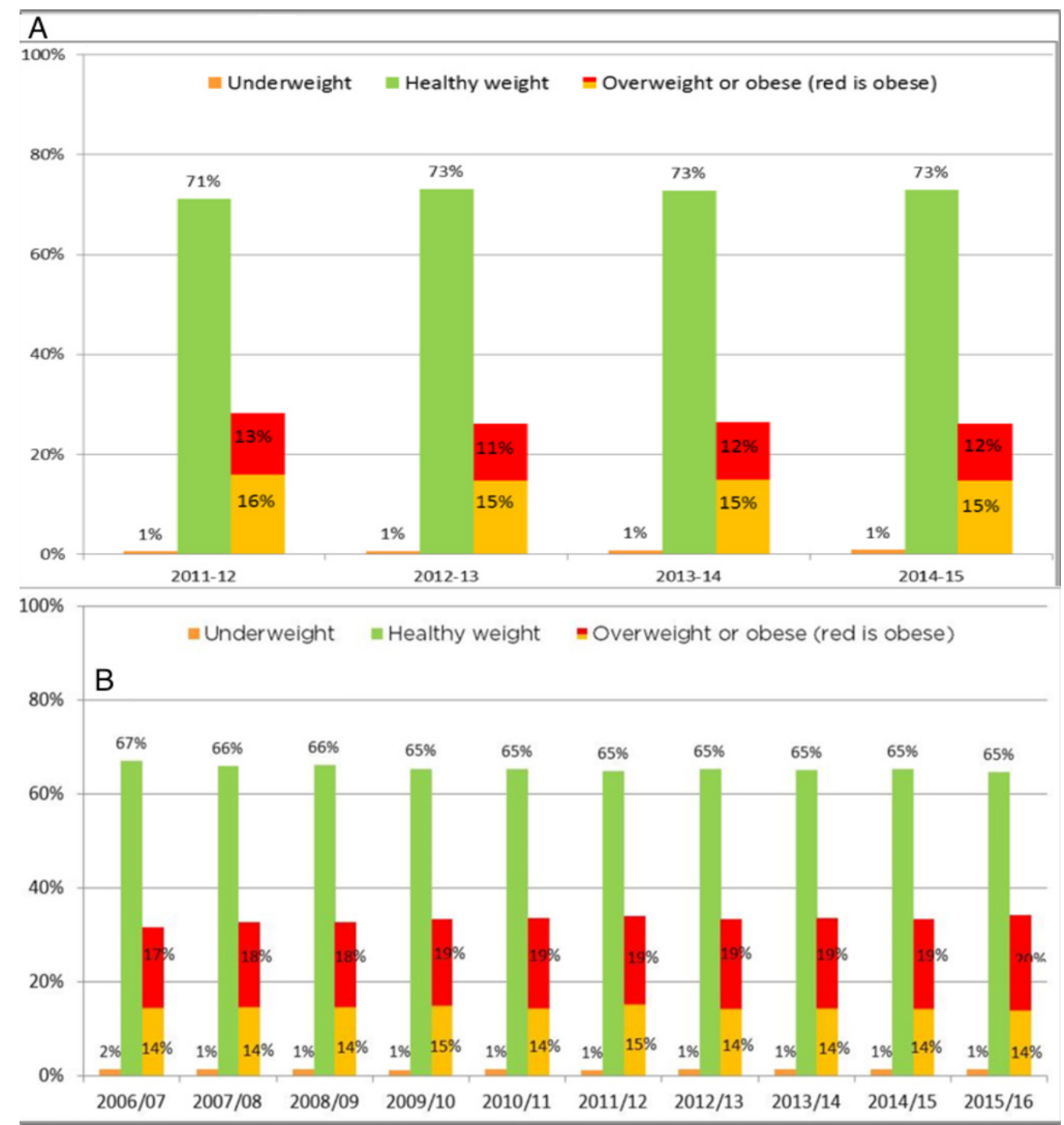

Figure 3 Proportion of children underweight, healthy weight, overweight or obese. (A) First year at primary school, Wales. ${ }^{34}$ (B) Final year at primary school, England. ${ }^{35}$ 


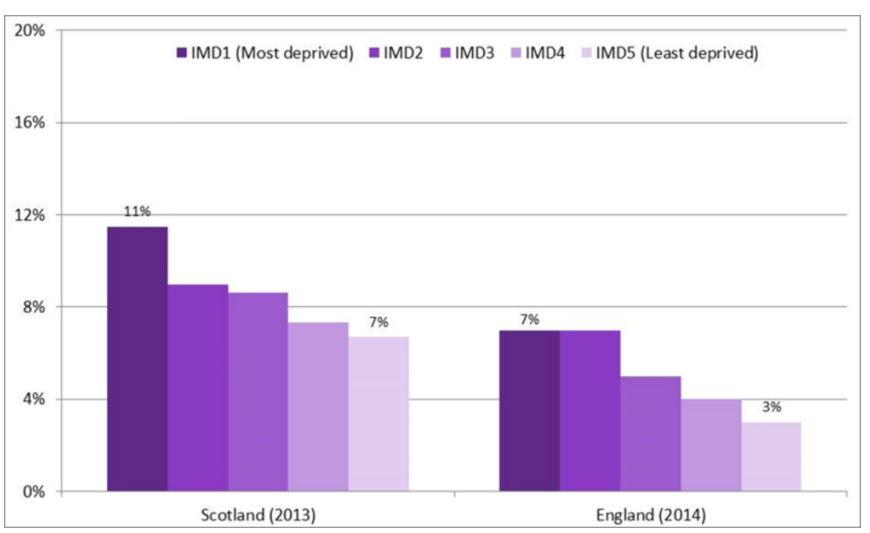

Figure 4 Proportion of regular smokers at age 15 by Index of Multiple Deprivation (IMD) quintiles in England ${ }^{36}$ and Scotland. ${ }^{37}$

greatest single cause of avoidable death in the UK and with smoking behaviour almost always established during adolescence, preventing CYP from smoking is a priority. CYP mentioned the various influences associated with smoking, including older siblings, family members and television or the media. ${ }^{19}$

While the negative health consequences caused by smoking are well established, CYP had mixed views concerning the use of electronic cigarettes (e-cigarettes), suggesting confusion as to the impacts and health risks of using e-cigarettes. An expert review conducted by Public Health England concludes that e-cigarettes are around 95\% safer than smoked tobacco and for CYP, it is better to remove the incentives to purchase e-cigarettes in order to reduce and denormalise the uptake of smoking. The marketing of e-cigarettes to CYP must be prohibited and further research is required to determine the impact that 'vape shops' and retailers selling e-cigarettes has on CYP. Public health authorities and government must also build on the suite of existing public health campaigns to extend the ban on smoking in public places to schools, playgrounds and hospitals.

Although alcohol use has significantly declined over the past decade, it still persists as a leading risk factor

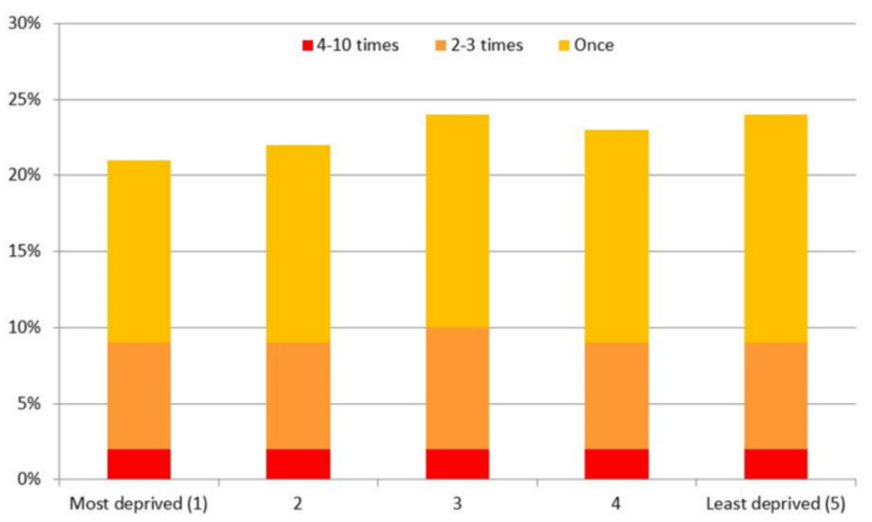

Figure 5 Frequency of drunkenness over the last 4 weeks of 15-year-old pupils in England who have had an alcoholic drink in their lifetime by Index of Multiple Deprivation Quintile. $^{36}$ for overall burden of disease in the UK. ${ }^{20}$ In 2013, 9\% of pupils in England drank alcohol in the previous week, compared with $25 \%$ in $2003,{ }^{21}$ which is a promising trend given the negative social and health outcomes alcohol has to young people. Prevention starts with ensuring young people have the knowledge and skills to make informed decisions about their health and well-being, making health promotion activities at school a vital opportunity for intervention.

Alcohol is the only indicator within the $\mathrm{SOCH}$ report that shows minimal or no correlation with social deprivation (figure 5), and in some instances alcohol use is more frequent among pupils from wealthier backgrounds, ${ }^{22} 23$ reflecting the position of alcohol as a commodity. With alcohol being 54\% more affordable in 2014 than in $1980,{ }^{24}$ it is vital that governments introduce and implement minimum unit pricing policies for alcohol. An independent review undertaken by Sheffield University, ${ }^{25}$ in addition to a growing volume of international research on minimum unit pricing policies, shows strong evidence to support the relationship between price increases and harm reduction. Given that CYP are more likely to consume cheaper drinks, introducing and implementing minimum unit pricing policies for alcohol across the UK will reduce and avoid the negative health outcomes associated with alcohol consumption in young people.

CYP are more likely to listen to people who have had their own experience of alcohol abuse. ${ }^{19}$ Schools must adopt comprehensive, evidence-based approaches to alcohol education that are tailored to reflect the local demographic of its pupils, as part of broader Personal Health and Social Education (PHSE). Training primary and secondary healthcare professionals to deliver extended brief interventions to young people aged 16-17 years who are drinking harmfully will help to steer these individuals towards less hazardous behaviours. ${ }^{26}$

\section{Key messages}

- Increase knowledge and awareness of the harms of smoking among CYP through statutory evidence-based PHSE.

- Extend bans on smoking in public places and in vehicles, coupled with sustained public health campaigns about the dangers of secondhand smoke for CYP.

- Protect and extend population level tobacco control measures and individual-level stop-smoking services for CYP and their parents.

- Continue to monitor the impact of e-cigarettes on smoking behaviour in CYP.

\section{Spotlight on inequality}

The most common issue exposed throughout the SOCH report was the links between poverty and poor health. Each of the indicators aside from alcohol had a strong social gradient, meaning that outcomes were worst among the poorest in our society compared with the wealthiest. These social gradients arise from inequity in the most basic social determinants of health-money, 
power, education-which then give rise to social gradients in health promoting or health risk behaviours. ${ }^{27}$ These social determinants may get under our 'get under our skin' from very early life, as poverty, stress, nutrition and parental behaviour in early life may influence a child's health outcomes lifelong. ${ }^{28}$ As data from the report shows us, children born in poverty are more likely to be born with a low weight, exposed to risks that perpetuate ill health and more likely to suffer from an injury resulting in death. ${ }^{29}$ Five-year olds living in the most-deprived areas of England, Northern Ireland and Wales are at least three times more likely to experience severe tooth decay than their more-affluent peers. They are more likely to smoke cigarettes, and will do so at a much younger age, significantly increasing the probability that they will smoke throughout adulthood which will attribute to the 96000 deaths caused by smoking in the UK each year. ${ }^{30}$ Despite increasing awareness of the social determinants of health and the pervasive nature of health inequalities, there is evidence that health inequalities among CYP have increased in the UK over the past two decades. ${ }^{31}$

It is disappointing to see that since this report was launched in January, several policy changes have been implemented in England that will affect households with more than two children and may even further push a quarter of a million children into poverty. ${ }^{32}$ Reducing child tax credits, scrapping the 'first child premium' in Universal Credit and removing housing benefit entitlement for 18-21 year olds are all likely to hasten the number of children who will have poorer chances of living healthy lives.

Over and over again, the indicators laid out in the report highlight the detrimental effect that child poverty has to the health and well-being of CYP in the UK. Each of the governments in the UK must as a moral duty create the optimal environment for children to survive and thrive. As a minimum this will require governments to coordinate efforts towards tackling child poverty and inequality so that all children, regardless of their wealth or status, will have equal access to healthcare and the chance to live healthy, prosperous lives.

\section{Four nations approach}

Data enable informed decisions to make comparisons and predict future outcomes. Data shine a light on what we are doing and enable improvements. SOCH 2017 highlighted notable gaps in data systems, both when comparing the four UK nations and when reporting on specific conditions and health measures. Data on CYP from Northern Ireland are particularly sparse.

Data that report on the prevalence of CYP's mental health conditions are urgently needed to enable better understanding where areas of deficiency require extra resource, but moreover to design and fund evidencebased services that are built around the needs of the child. That data are missing from important areas that require robust interventions, namely maternal health and obesity, means there is a huge risk the CYP who require services and support are not receiving them and the opportunity for prevention and early intervention is missed, leading to increasing costs for treatment and interventions later in their lives. An expansion of programmes to measure the height and weight of children throughout their life course into adulthood is also critical if we are to monitor trends and in doing so, it will identify pivotal points during childhood in which to effectively intervene and prevent children becoming overweight and obese into adulthood.

There is no doubt that strengthening of routine data collection should be a priority to allow key child health issues to be closely monitored and linked to policy initiatives with appropriate process and outcome measures.

\section{What's next for policy and practice?}

Poor child health outcomes in the UK, together with widening inequalities are a harbinger of poorer economic productivity in adult life, chronic ill health and frailty in old age, and greater ultimate burden on health services. Today's children are the workers of tomorrow and the parents of the next generation. Our poor outcomes are a particular concern as UK heads towards Brexit, when the productivity of our workforce will determine whether we do well as a nation.

Child health and well-being must be at the top of the political agenda. Healthy children are more likely to grow into healthy adults, increasing economic productivity and reducing the burden on health services in old age. To ensure the health of infants, CYP in the UK is the best in the world, coordinated government action across all departments is required. This is why each UK government must, as a matter of urgency, develop an evidencebased strategy, coordinated, implemented and evaluated across the UK, with a clear accountability framework. We urge all UK governments to adopt the $25 \mathrm{SOCH}$ indicators as agreed key CYP health indicators to plan strategy and track progress, in the way that similar 'Headline Indicators' are used in Australia. ${ }^{33}$

At the time of writing, governments in Scotland and Wales are using the findings of SOCH 2017 to begin to develop new child health strategies.

Governments must also introduce 'levelling policies' to ensure that all children have the best start in life. This means recognising the wider determinants of health and well-being, including good housing, air quality, diet and nutrition, opportunities to be physically active, and to be brought up in a secure, nurturing environment. A 'child health in all policies' approach is needed to ensure that all national policy, including economic policy, passes the test of no negative impact on child health and well-being.

Achieving good child health and well-being has to be a priority at the highest level for the next government as this is the most important determinant of the health of the adult population and a healthy old age. Improving child health makes moral, scientific and economic sense 
and would be the best of investments for the nation, with the greatest long-term return.

Contributors The paper was conceptualised and planned by EKA and RV. The first draft of the paper was written by MA and MS, supervised by EKA. RV and EKA edited the first draft and prepared the final document. EKA and RV guarantee the paper.

Competing interests None declared.

Provenance and peer review Commissioned; externally peer reviewed.

Open Access This is an Open Access article distributed in accordance with the Creative Commons Attribution Non Commercial (CC BY-NC 4.0) license, which permits others to distribute, remix, adapt, build upon this work non-commercially, and license their derivative works on different terms, provided the original work is properly cited and the use is non-commercial. See: http://creativecommons.org/ licenses/by-nc/4.0/

(C) Article author(s) (or their employer(s) unless otherwise stated in the text of the article) 2017. All rights reserved. No commercial use is permitted unless otherwise expressly granted.

\section{REFERENCES}

1. Viner RM. State of Child Health: Report 2017. London: Royal College of Paediatrics \& Child Health, 2017.

2. Viner RM, Coffey C, Mathers C, et al. 50-year mortality trends in children and young people: a study of 50 low-income, middleincome, and high-income countries. Lancet 2011;377:1162-74.

3. Chief Medical Officer. Annual Report of the Chief Medical Officer's annual report 2012: Our Children Deserve Better: Prevention Pays. London: Department of Health, 2013.

4. Viner RM, Hargreaves DS, Coffey C, et al. Deaths in young people aged 0-24 years in the UK compared with the EU15+ countries, 1970-2008: analysis of the WHO Mortality Database. Lancet 2014:384:880-92.

5. Mental Health Foundation. Fundamental Fact About Mental Health 2015.

6. World Health Organisation. Chapter 9: Pregnancy and postpartum smoking cessation. Gender, women, and the tobacco epidemic, 2010:179-88.

7. Information Services Division Scotland. Maternal Smoking at the First Visit: Financial Years 2005/06 - 2014/15: Information Services Division Scotland. 2015 http://www.isdscotland.org/Health-Topics/ Maternity-and-Births/Publications/data-tables.asp (updated 20 April 2016).

8. Weiser TM, Lin M, Garikapaty V, et al. Association of maternal smoking status with breastfeeding practices: Missouri, 2005. Pediatrics 2009;124:1603-10.

9. World Health Organisation. Infant and young child nutrition. 55th World Health Assembly, 2002.

10. Public Health Agency. Children's Health in Northern Ireland, 2016.

11. Information Services Division Scotland. Breastfeeding Statistics Scotland, 2015.

12. The Lancet. Webappendix 4: Lancet Breastfeeding Series paper 1, Data Sources and estimates: countries without standardized surveys. Lancet 2016;17.

13. McAndrew F, Thompson J, Fellows L, et al. Infant Feeding Survey 2010: Health and Social Care Information Centre, 2012.

14. Horta BL, Loret de Mola C, Victora CG. Long-term consequences of breastfeeding on cholesterol, obesity, systolic blood pressure and type 2 diabetes: a systematic review and meta-analysis. Acta Paediatr 2015;104:30-7.
15. UNICEF UK. What is the baby friendly initiative? UNICEF UK, 2016. https://www.unicef.org.uk/babyfriendly/what-is-baby-friendly/ (accessed 6 Apr 2016).

16. RCPCH Position Statement. breastfeeding in the UK. London: Royal College of Paediatrics \& Child Health, 2017.

17. World Health Organisation. Report of the commission on ending childhood obesity, 2016

18. Viner RM, Ozer EM, Denny S, et al. Adolescence and the social determinants of health. The Lancet 2012;379:1641-52.

19. Royal College of Paediatrics and Child Health. \&US RCPCH Voice Bank, 2016

20. Murray CJ, Richards MA, Newton JN, et al. UK health performance: findings of the Global Burden of Disease Study 2010. Lancet 2013;381:997-1020.

21. Health and Social Care Information Centre. Smoking drinking and drug use among young people in England in 2014. England: Health and Social Care Information Centre, 2015. https://www.gov.uk/ government/statistics/smoking-drinking-and-drug-use-amongyoung-people-in-england-2014.

22. Viner RM, Ozer EM, Denny S, et al. Adolescence and the social determinants of health. Lancet 2012;379:1641-52.

23. World Health Organisation. Growing up unequal: gender and socioeconomic differences in young people's health and wellbeing. Health Behaviour in School-aged Children (HBSC) study: international report from the 2013/2014 survey. Copenhagen: WHO, 2016.

24. Centre HSCl. Statistics on Alcohol 2015. http://content.digital.nhs. uk/catalogue/PUB17712/alc-eng-2015-rep.pdf.

25. Booth A, Meier P, Stockwell T, et al. Independent review of the effects of alcohol pricing and promotion. Part A: systematic reviews: University of Sheffield, 2008.

26. National Institute for Health and Care Excellence. Alcohol-use disorders: prevention: National Institute for Health and Care Excellence, 2010. https://www.nice.org.uk/guidance/ph24?unlid=72 4058922201686173156 (Epub ahead of print Jun 2016).

27. Commission on Social Determinants of $\mathrm{H}$. Closing the gap in a generation: health equity through action on the social determinants of health. Geneva: World Health Organisation, 2008.

28. Irwin LG, Siddiqi A, Hertzman C. Early child development: a powerful equalizer Early Childhood Knowledge Network Final Report of the Early Childhood Knowledge Network of the Commission for the Social Determinants of Health, 2007.

29. Roberts J, Bell R. Social Inequalities in the Leading causes of early death a life course approach: UCL Institute of Health Equity, 2015.

30. ASH. Facts at a glance: smoking and disease: ASH, 2016.

31. Hargreaves DS, Djafari Marbini A, Viner RM. Inequality trends in health and future health risk among English children and young people, 1999-2009. Arch Dis Child 2013;98:850-5.

32. Asthana PBA. Welfare shakeup 'will push a quarter of a million children into poverty'. The Guardian 2017 (2 Apr 2017).

33. Blair M, Hiscock $\mathrm{H}$. Themes emerging from State of Child Health: UK and Australia. Arch Dis Child 2017:archdischild-2017-312875 (Epub ahead of print $25 \mathrm{Jul}$ 2017).

34. Public Health Wales. Child Measurement Programme for Wales: Public Health Wales. http://www.wales.nhs.uk/sitesplus/888/page/ 67762.

35. Health and Social Care Information Centre. National Child Measurement Programme: Health and Social Care Information Centre. http://www.hscic.gov.uk/ncmp.

36. Health and Social Care Information Centre, Ipsos Mori. Health and Wellbeing of 15 year olds in England - Main Findings from the What About YOUth? Survey 2014. 2nd ed, 2015.

37. NHS National Services Scotland. Scottish Schools Adolescent Lifestyle and Substance Use Survey (SALSUS) NHS National Services Scotland/Crown Copyright 2014, 2015. 